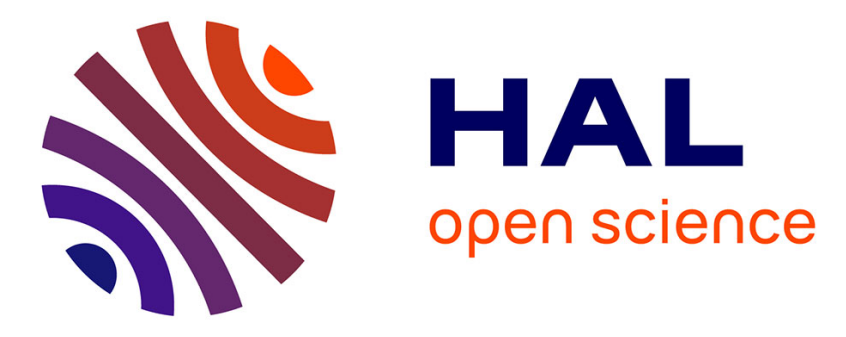

\title{
New Circularly Polarized Matrix Antenna For Space Applications
}

Ali Siblini, Bernard Jecko, Hussein Abou Taam, Mohamed Rammal, Anthony Bellion

\section{- To cite this version:}

Ali Siblini, Bernard Jecko, Hussein Abou Taam, Mohamed Rammal, Anthony Bellion. New Circularly Polarized Matrix Antenna For Space Applications. WTS 2016 15th annual wireless telecommunications symposium, Apr 2016, London, France. hal-01321034

\section{HAL Id: hal-01321034 \\ https://hal.science/hal-01321034}

Submitted on 24 Jun 2016

HAL is a multi-disciplinary open access archive for the deposit and dissemination of scientific research documents, whether they are published or not. The documents may come from teaching and research institutions in France or abroad, or from public or private research centers.
L'archive ouverte pluridisciplinaire HAL, est destinée au dépôt et à la diffusion de documents scientifiques de niveau recherche, publiés ou non, émanant des établissements d'enseignement et de recherche français ou étrangers, des laboratoires publics ou privés. 


\title{
New Circularly Polarized Matrix Antenna For Space Applications
}

\author{
Ali Siblini ${ }^{1}$, Bernard Jecko ${ }^{1}$ \\ ${ }^{1}$ Dept. OSA, XLIM, UMR CNRS $n^{\circ} 7252$, \\ Limoges University, 78000 Limoges. \\ ali.siblini@unilim.fr \\ bernard.jecko@unilim.fr
}

\author{
Hussein Abou Taam², Mohamed \\ Rammal $^{2}$ \\ ${ }^{2}$ Doctoral School of Science and \\ Technology, Lebanese University, Lebanon.
}

\author{
Anthony Bellion ${ }^{3}$ \\ ${ }^{3}$ CNES, 18 Avenue Edouard Belin, 31401 \\ Toulouse Cedex 9, france. \\ Anthony.Bellion@.cnes.fr
}

\begin{abstract}
- this paper presents a new electromagnetic approach of matrix antenna, specialized for circularly polarized space applications. The design of the proposed antenna matrix is based on small pixels which generate circular polarization field. The concept of the pixels is well demonstrated as a patent and verified for the use in antenna arrays. The design will be used for several space applications with directive and wide angle beams.

Index Terms-antenna array, axial ratio, beam forming, Isoflux, Electromagnetic band gap material EBG, Frequency selective surface FSS.
\end{abstract}

\section{INTRODUCTION}

Space communication has forced the use of Circular polarization. The fundamental advantage of circular polarization is that it solves the problems of polarization changes due to the reflections that occur during signal travelling from space station to land stations. Therefore we can avoid fading and flutter when circular polarization is used at each end of the link.

Space applications at large, medium and low height orbits act at different bands especially in the range 1-40 GHz from the L-band up to the ka-band. Such applications insure several services such as global positioning systems, cellular communications, direct broadcasting, marine communications and other applications.

Various antennas are used in the space stations such as parabolic [1], helical [2], and array antennas. However increase in technology leads to a wide range of services and applications that require more specialized specifications. Specifications are mainly the small size for the development of mini satellites and the agility of beam forming. Agility in beam forming requires antennas that function with different patterns such as directive beam, multi directive beams and large angle beam that is widely known as isoflux. In the context of this paper the designed matrix antenna is based on MARPEM (in French) or ARMA (English) [3], [4], [5], [6], [7], which overcomes the AESA (Agile electronically scanned arrays) limitations [8]. The matrix will show the new agility of beam forming, while maintaining a good circular polarization over a wide angle of radiated beam.

\section{PIXEL DESIGN}

The element which appears to be most important to ensure the system ARMA good approximation of the desired radiating surfaces is so-called elementary source "Pixel". This pixel is deducted from EBG antennas but has characteristics especially concerning the special electromagnetic radiating shape formed in its upper surface. The pixel provides a radiating surface of preferential form square with an almost uniform distribution of electromagnetic fields on pixel dimensions.

The design is adapted on the $\mathrm{X}$-band $[8-8.4 \mathrm{GHz}]$ centered at $8.2 \mathrm{GHz}$. A pixel of size $0.5 \lambda \times 0.5 \lambda$ is designed with a substrate of 2.94 permittivity and height $\mathrm{h}=1.52 \mathrm{~mm}$ for the patch and the FSS (fixed on the top face of the pixel). The pixel is fed by four probes. The metallic walls built at the four edges of the ground plane ensure the square radiating surface. The metallic walls, ground plane and the FSS form a cavity. The EBG cavity limited by the FSS will be the feeding source for the FSS. Fig. 1 shows the pixel structure.
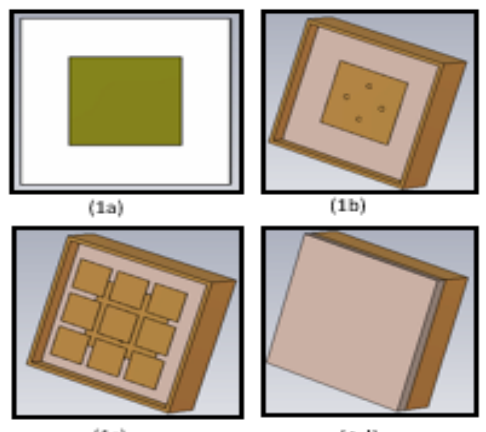

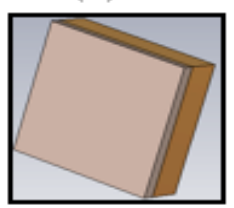

(1d)

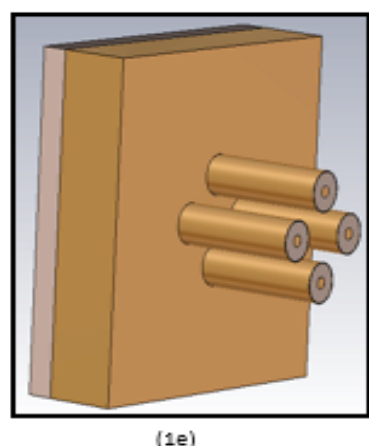

[1e]
Figure 1. (1a) patch, (1b) patch with metallic walls, (1c) adding the FSS on top, (1d) substrate on top, (1e) the four feeding cables. 


\section{FEEDING CIRCUIT DESIGN}

The sequential phase shifted $\left(0^{\circ}, 90^{\circ}, 180^{\circ}\right.$ and 270$)$ equally amplitude feeding sources are used to make the circular polarization. For this aim a feeding circuit is designed to feed the pixel probes. Fig. 2 shows the circuit. The circuit is based on three $90^{\circ}$ hybrid couplers [9] printed on a substrate hydrocarbon ceramic of permittivity 12.2 and height $\mathrm{h}=0.4 \mathrm{~mm}$. In the perfect feeding procedure used in CST, we introduce the equal magnitudes inputs for the ports of the pixel. In this perfect case the ports phases are $0^{\circ}, 90^{\circ}, 180^{\circ}$, and 270 . The circuit should give outputs results near the perfect case. So the use of the hybrid coupler ensures high stability of the magnitudes and phases over the required bandwidth. The circuit has maximum phase error of $3^{\circ}$ and maximum magnitude error of $0.45 \mathrm{~dB}$.

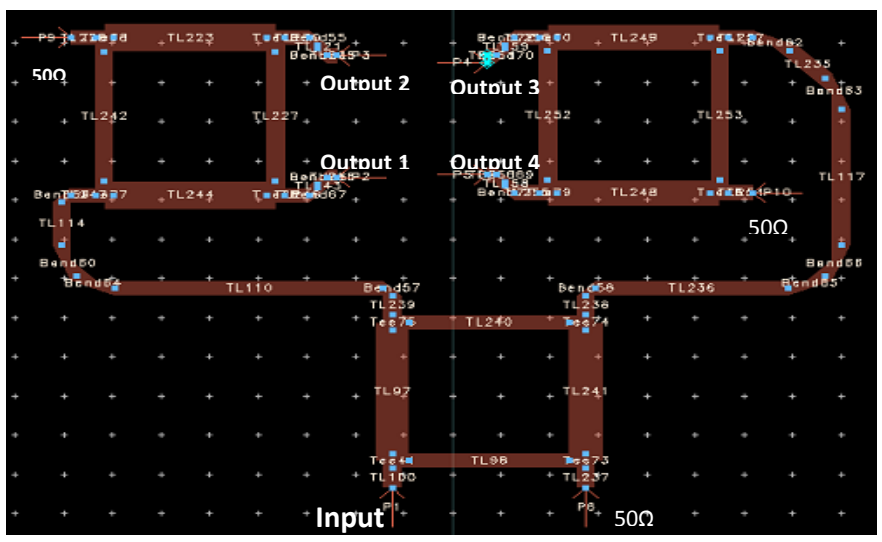

Figure 2. Circuit of three hybrid couplers.

\section{SiMULATION RESULTS OF THE PIXEL WITH THE CIRCUIT}

The circuit is simulated with the pixel and with a classical patch antenna with four feeding probes. In both cases the outputs of the circuit are connected to the four input probes. Fig. 3 shows the comparison of the bandwidth that is $8.8 \%$ in the pixel and $3.9 \%$ in the patch. The pattern and the axial ratio of the pixel are shown in Fig. 4 and Fig. 5 respectively. The axial ratio is below $3 \mathrm{~dB}$ over a wide angle $\pm 71^{\circ}$. And the maximum gain attained is $6.55 \mathrm{~dB}$.

The radiating surface of the pixel is shown in Fig. 6, where the square field shape is formed all over the dimensions of the pixel.

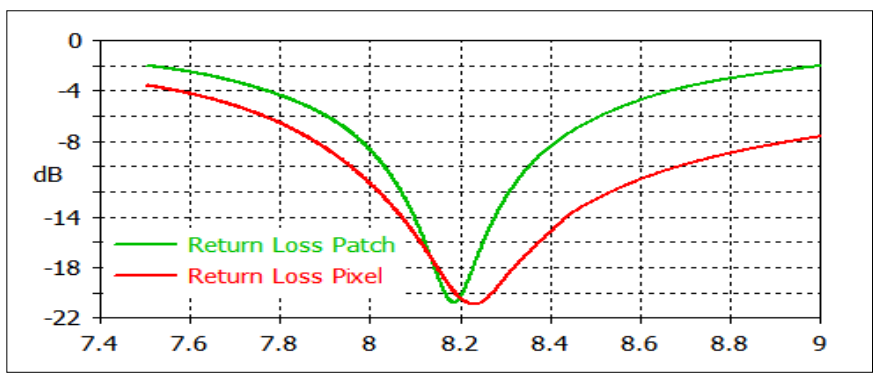

Figure 3. Comparison of return loss for the patch and the pixel.

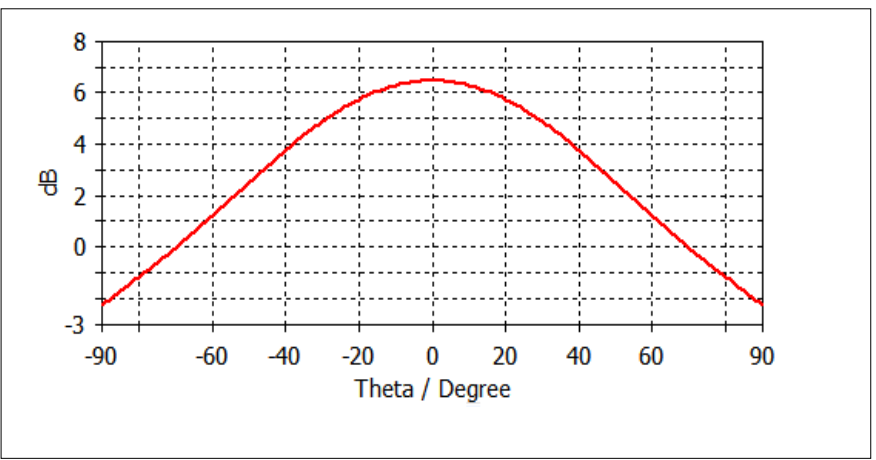

Figure 4. Pixel gain pattern in $\mathrm{dB}$ at $8.2 \mathrm{GHz}$, azimuth plane $0^{\circ}$

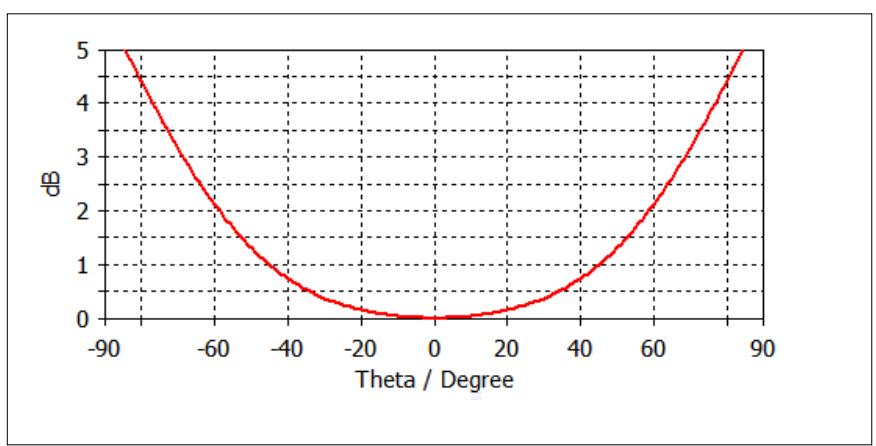

Figure 5. Pixel axial ratio at $8.2 \mathrm{GHz}$, azimuth plane $0^{\circ}$.

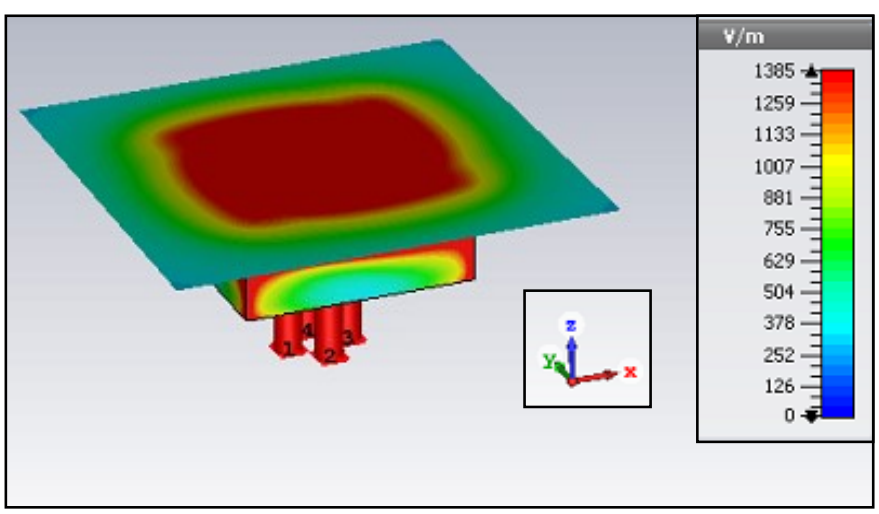

Figure 6. Near field for pixel element of the matrix.

\section{DESIGN AND SIMULATION RESULTS OF THE MATRIX}

2D matrix is designed based on $5 \times 5$ pixels. Fig. 7 shows the matrix. The concept of matrix antenna beam forming requires sampling of the total surface. Each sample is an element pixel. So, the uniform jointed squared radiating surfaces of the pixels improve the sampling method. A comparison is made with the classical $5 \times 5$ patch array where the elementary patch is fed also by four probes to form the circular polarization. Fig. 8 compares the coupling coefficient of the central pixel/patch and other pixels/patches. Almost the coupling in ARMA is less by $4-5 \mathrm{~dB}$. 


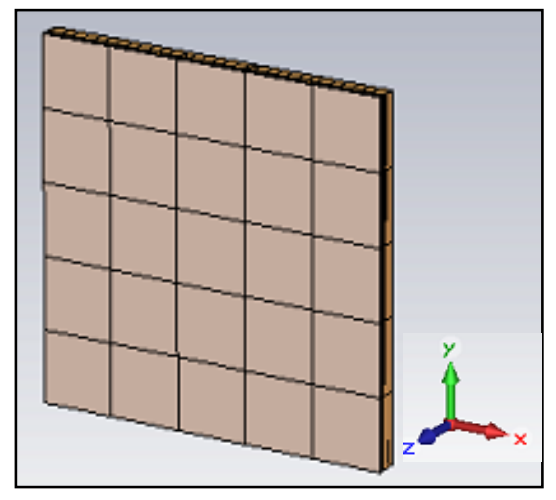

Figure 7. Matrix antenna 5x5 pixels.

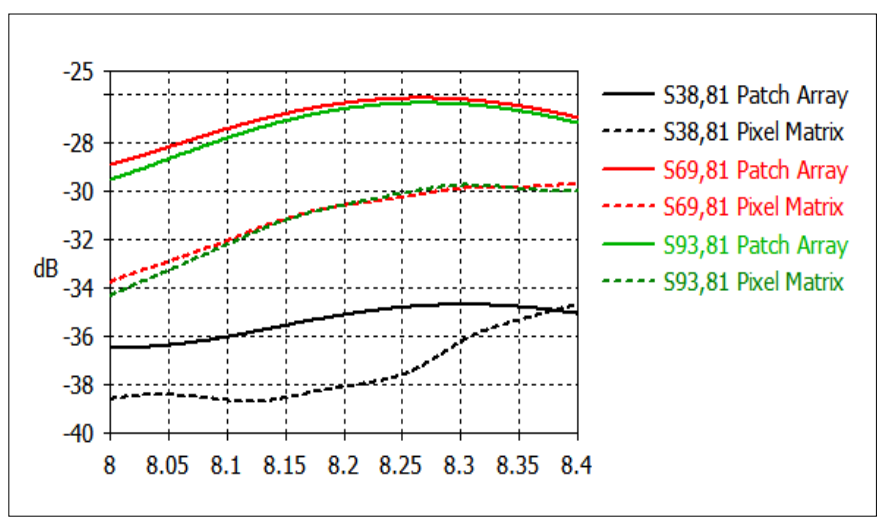

Figure 8. Coupling between the port 81 and other ports (Patch Array/ Pixel Matrix).

Example of beam forming is the isoflux diagram. It's widely studied [10] and used for the aim of space-terrestrial applications that require wide coverage angle of power delivered to the earth [11] as shown in Fig.9. Min-Max algorithm of phased array antenna synthesis [12] is used to find the best feeding currents phases and magnitudes to generate such an isoflux. Fig. 10 and shows the magnitudes and phases of the $5 \times 5$ matrix.

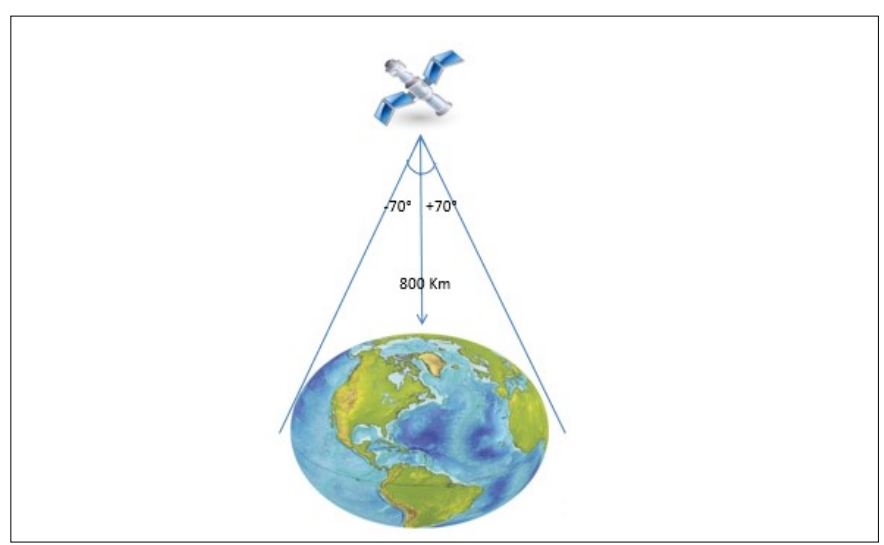

Figure 9. Satellite observation of the earth from low orbit LEO.

\begin{tabular}{|c|c|c|c|c|}
\hline$\left(0,0^{\circ}\right)$ & $\left(0.02,0^{\circ}\right)$ & $\left(0.01,0^{\circ}\right)$ & $\left(0.02,0^{\circ}\right)$ & $\left(0,0^{\circ}\right)$ \\
\hline$\left(0.02,0^{\circ}\right)$ & $\left(0.03,180^{\circ}\right)$ & $\left(0.13,180^{\circ}\right)$ & $\left(0.03,180^{\circ}\right)$ & $\left(0.02,0^{\circ}\right)$ \\
\hline$\left(0.01,0^{\circ}\right)$ & $\left(0.13,180^{\circ}\right)$ & $\left(1,0^{\circ}\right)$ & $\left(0.13,180^{\circ}\right)$ & $\left(0.01,0^{\circ}\right)$ \\
\hline$\left(0.02,0^{\circ}\right)$ & $\left(0.03,180^{\circ}\right)$ & $\left(0.13,180^{\circ}\right)$ & $\left(0.03,180^{\circ}\right)$ & $\left(0.02,0^{\circ}\right)$ \\
\hline$\left(0,0^{\circ}\right)$ & $\left(0.02,0^{\circ}\right)$ & $\left(0.01,0^{\circ}\right)$ & $\left(0.02,0^{\circ}\right)$ & $\left(0,0^{\circ}\right)$ \\
\hline
\end{tabular}

Figure 10. Magnitude and phase distribution of the $5 \times 5$ matrix antenna.

These magnitudes and phases are applied to the $5 \times 5$ ARMA antenna and the $5 \times 5$ patch array. Fig. 11 shows the gain pattern comparison in the azimuth plane $45^{\circ}$, where the isoflux gain pattern is wider by $11^{\circ}$ in ARMA. These results are in general the same for the other azimuth planes. So ARMA is more efficient for the wide coverage area applications, especially for the low orbits space stations (LEO). However the more important is the circular polarization stability at this wide coverage angles that is below $3 \mathrm{~dB}$ in between $\pm 80^{\circ}$ in most of the azimuth planes. Fig. 12 shows the axial ratio for ARMA in two azimuth planes.

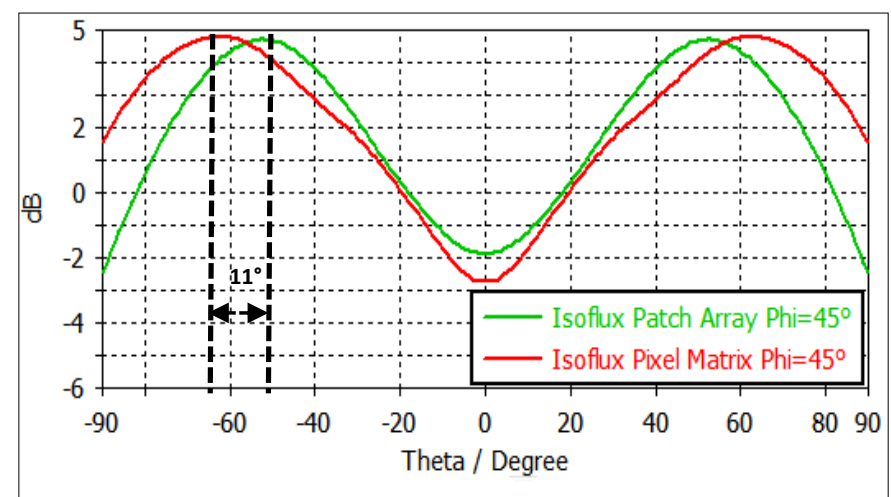

Figure 11. Gain pattern of the $5 \times 5$ MARPEM and $5 \times 5$ Patch array at $8.2 \mathrm{GHz}$ azimuth plane $45^{\circ}$.

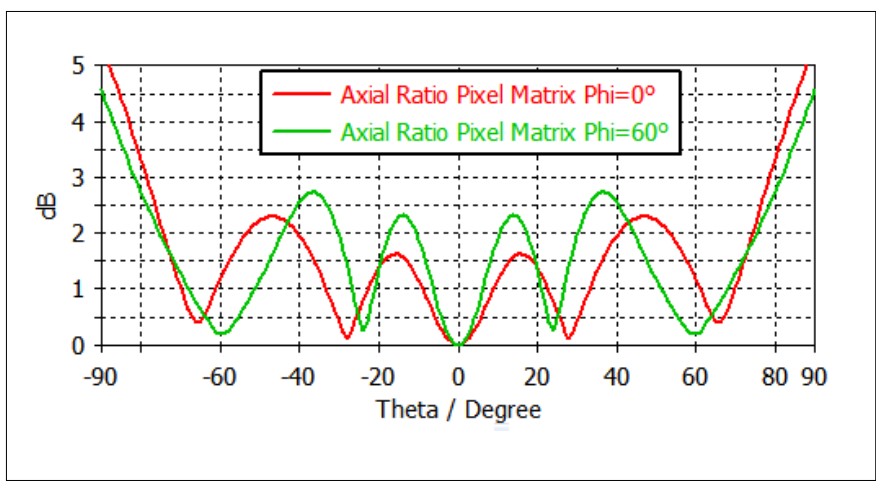

Figure 12. Axial ratio at $8.2 \mathrm{GHz} 5 \times 5 \mathrm{MARPEM}$, azimuth planes $0^{\circ}, 60^{\circ}$. 


\section{CONCLUSION}

In this paper ARMA is used to improve the antenna performances in the circular polarization space applications. The pixels are used to generate the jointed radiating surfaces which give circularly polarized radiating field. The pixel and matrix design show high stability of the axial ratio, over the wide angle of the beam required for the near orbits. This antenna is in the step of fabrication funded by CNES. Thanks for CNES for the funding of the project.

\section{REFERENCES}

[1] Improving the beam effeciency oa an offse parabolic refelector antenna spacebone radiometric applications. Department of Electronics \& Communications Engineering Institute of Technology Nirma University Ahmedabad-382481, India.

[2] Helical Antennas in Satellite Radio Channel Maja Škiljo and ZoranBlažević University of Split, Faculty of electrical engineering, mechanical engineering and naval architecture, Croatia

[3] B.Jecko,M.Hajj,R.Chantalat,andM.SalahToubet, “Antene elementaire et antenne reseau mono ou bidimensionnelle correspondante," PCT Patent PCT/EP2012/076509, University of Limoges, Limoges, France, 2013.

[4] Étude d'une Matrice Agile Rayonnante à Pixels Elaborés en Métamatériaux Maîtrise de concepts, Réalisation de Prototypes et Caractérisation. XLIM - Département Ondes et Systèmes Associés Ecole Doctorale des Sciences et de Technologie.

[5] A New Agile Radiating System Called Electromagnetic Band Gap Matrix Antenna ». Auteurs: Hussein ABOU TAAM, Moustapha
SALAH TOUBET, Thierry Monedière, Bernard JECKO, Mohamed RAMMAL. Journal: International Journal of Antennas and Propagation, vol. 2014, Article ID342518, 7 pages, 2014.

[6] Radiation control of an agile Matrix antenna by using specific algorithm Auteurs: Hussein ABOU TAAM, Moustapha SALAH TOUBET, Thierry Monedière, Bernard JECKO, Mohamed RAMMAL.

[7] 1D Ultra Low-Profile EBG matrix for radar applications. Auteurs: Moustapha SALAH TOUBET, Hussein ABOU TAAM, Bernard JECKO, Mohamed RAMMAL. Conférence: IEEE, RadarCon conference, 29 April - 3 May 2013, Canada.

[8] An Agile Electronically Scanned EBG Matrix Antenna For Monitoring Target Activity. Hussein Abou Taam, Ali Siblini1, Georges Zakka El Nashef1, Bernard Jecko1, Eric Arnaud, Nicolas Chevalier. XLIM OSA (Ondes et Systèmes Associés) Limoges University Limoges, France.

[9] L. Chiu and Q. Xue, "Investigation of a Wideband $90^{\circ}$ Hybrid Coupler With an Arbitrary Coupling Level," in IEEE Transactions on Microwave Theory and Techniques, vol. 58, no. 4, pp. 1022-1029, April 2010.

[10] X-band compact choke horn antenna with circular polarization and isoflux pattern fornanosatellite applications. Eric Arnaud, Luc Duchesne, kevin Elis, Jamil Fouany, Thierry Monediere and Marc Thevenot.

[11] Circularly Polarized Isoflux Compact X Band Antenna for Nano Satellites Applications Authors: J. Fouany, M. Thevenot, Eric Arnaud, F. Torres, T. Monédière, N. Adnet, L. Duchesne, J.M. Baracco, K. Elis. XLIM, France; SATIMO, France; CNES, France.

[12] Contribution of study and synthesis of the printed antenna arrays. Application on the conception of array beam forming. Thesis at Limoges university, Mohamad Rammal, 29 january 1993. 